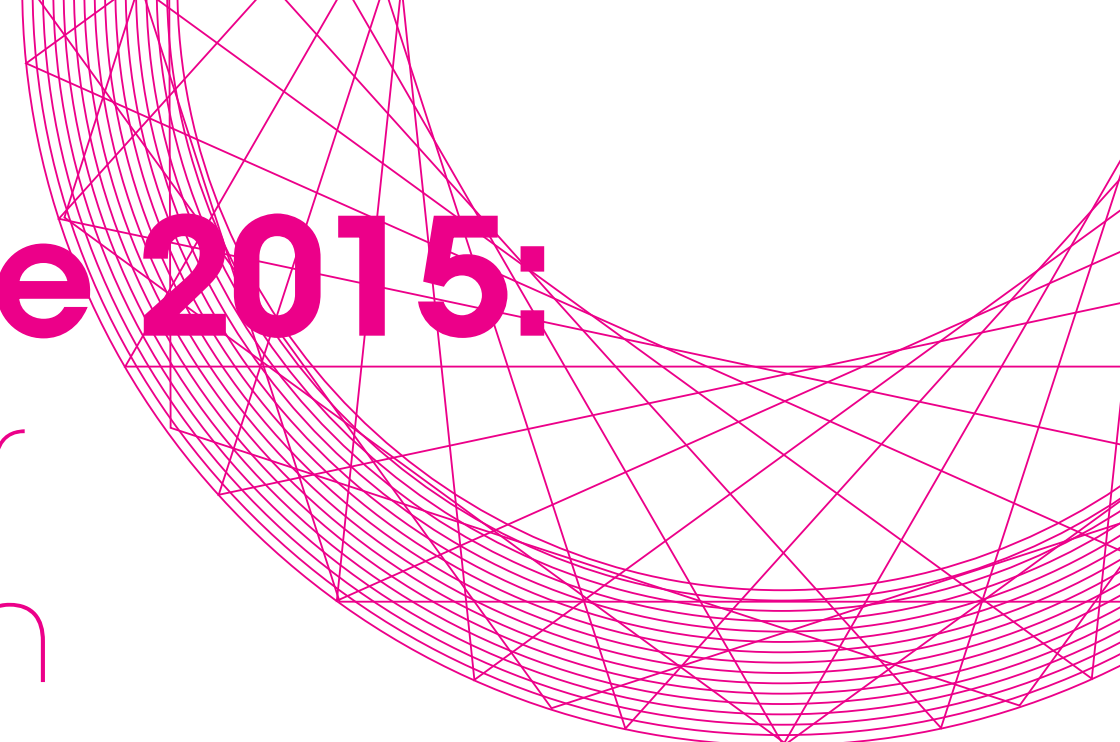

$\mathrm{W}$

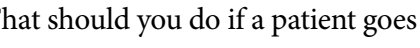
into anaphylactic shock? What measures should you take to keep your equipment sterile? How would you deal with a patient complaint? What about making sure not to miss the early signs of oral cancer? The answer to all these questions will be covered in the core CPD sessions at next year's British Dental Conference and Exhibition.

A total of up to 15 hours' verifiable CPD (core and elective) can be achieved by attending the event. Your attendance at each session will be registered electronically using your delegate badge and you will be able to download your CPD certificate after the event.

Sessions marked as core CPD in next year's programme will cover topics that the GDC highly recommends all dental professions cover as part of their minimum verifiable CPD requirement. All the topics are covered in depth and you have the chance to gain different perspectives from a variety of experts.

\title{
LEGAL AND ETHICAL ISSUES
}

From understanding consent to knowing what to put in a patient's records, these sessions have got it covered.

\section{Thursday 7 May 2015}

The only way is ethics - a comprehensive update on consent, equality, diversity and ethics

Speaker:

Thomas O'Connor, GDP, Cambridge; Quality Improvement Fellow, Health Education East of England and Honorary Speciality Registrar Cambridge University Teaching Hospitals

Friday 8 May 2015 Hitting the right notes Speaker:

Andy Hadden, Dento-legal Adviser and Chief Fellowship Assessor, FGDP

\section{Saturday 9 May 2015}

How good is your record keeping? How to protect yourself and your practice

Speaker:

Richard Birkin,

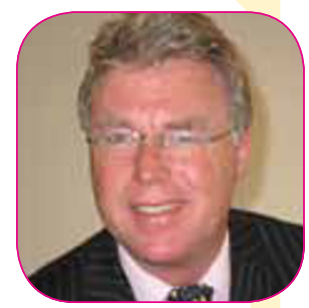

National Director, BDA Wales

The GDC fitness to practise process - does it work?

Speakers:

Richard Hayward Specialist in Oral Surgery, Derbyshire and Stephen Henderson, Senior Dento-legal Advisor, Dental Protection

\section{COMPLAINTS HANDLING}

Learn the benefits of positive patient communication, and how to effectively handle complaints and minimise escalation.

\section{Thursday 7 May 2015}

Learn to love complaints

Speaker:

Janine Brooks MBE, Associate

Postgraduate Dental Dean, Thames

Valley and Wessex, Health Education England and Lead Clinical Tutor, Law and Ethics Unit, Bristol University BUOLD programme

\section{Friday 8 May 2015}

Handling patient complaints successfully

Speaker:

Heather Dallas,

Managing Director,

Dallas Development

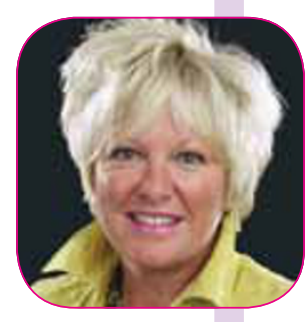

Book your place before Monday 9 February 2015 to secure the early bird price!

For more information and to register, visit www.bda.org/conference

\section{DISINFECTION AND DECONTAMINATION}

The GDC recommends that you do at least five hours' CPD in this area in every five year cycle to help protect you and your patients.

\section{Thursday 7 May 2015}

Infection control essentials

Speaker: Edward Sinclair, Practice Management Consultant (Health and Safety), British Dental Association

\section{Saturday 9 May 2015}

Cross infection control/ decontamination

Speaker: Paul Jenkins, Decontamination Manager, North Bristol NHS Trust

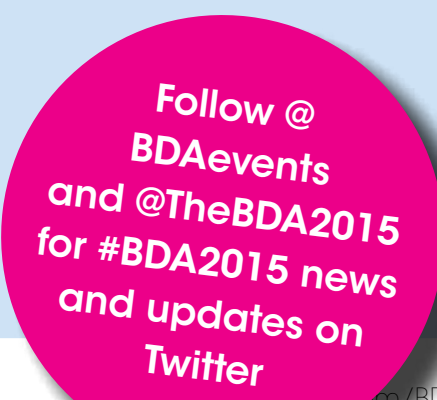




\section{RADIOGRAPHY AND RADIATION PROTECTION}

This is another area which the GDC recommends you cover at least five hours in every CPD cycle.

\section{Thursday 7 May 2015}

To expose or not to expose, that is the question. The role of the IR(ME)R practitioner in dose reduction

Speaker:

Jane Luker, Senior Clinical Lecturer, Oral and Dental Sciences, University of Bristol and Dental Postgraduate Dean for Health Education South West

\section{Friday 8 May 2015}

Developments in dental radiology for the practitioner

Speaker:

Nicholas Drage, Consultant in Dental and Maxillofacial Radiology, University Dental Hospital, Cardiff

Radiation doses in dental radiography: factors affecting dose and dose reduction Speaker:

Paul Nixon, Consultant in Maxillofacial Radiology, Liverpool Dental Hospital

\section{MEDICAL EMERGENCIES}

The GDC recommends a minimum of ten hours verifiable CPD each five year cycle should cover medical emergencies, with at least two hours each year. You will have no problem gaining this in Manchester with a range of sessions in the Conference and Exhibition Hall programme covering a range of emergencies you might encounter.

\section{Thursday 7 May 2015}

The management of anaphylaxis, asthma, angina and hypoglycaemia in general dental practice Speaker:

Raj Majithia, GDP, London and Associate Dean, London Dental Education and Training

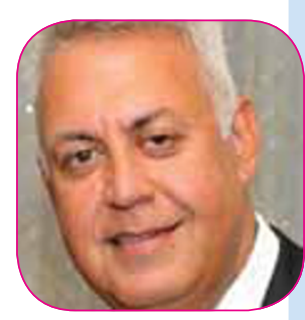

Medical emergencies AND Managing emergencies in the dental practice

Speakers:

Kathryn Taylor and Julie Burke, Specialists and Lecturers in Oral Surgery, Leeds Dental Institute

Friday 8 May 2015 Preventing and managing medical emergencies

Speaker:

Peter Whiteford, Resuscitation Adviser, Medical Emergency Training
Medical emergencies - angina and heart attack with Automated External Defibrillation (AED)

Speaker: Peter Whiteford, Director, Medical Emergency Training

\section{Saturday 9 May 2015}

Medical emergencies in the dental surgery

Speaker: Abbas Zaidi, Cardiology Specialist Registrar, Wales Deanery Medical emergencies anaphylaxis and intramuscular injection techniques

Speaker: Peter Whiteford,

Director, Medical Emergency Training
ORAL

CANCER

Early detection of oral cancer can save lives. Some of these sessions will help you know what to look for; others will focus on current research and discoveries to keep you informed.

\section{Thursday 7 May 2015}

Oral cancer: prevention and early detection (Training Essentials theatre)

Speaker:

Mike Pemberton, Consultant in Oral Medicine and Clinical Head of Division, University Dental Hospital of Manchester

\section{Friday 8 May 2015}

Well, why worry? ... You don't get pregnant with oral sex!

Speaker:

Val McMunn, Lecturer in Contraception and Sexual Health, City University London and Independent Nurse Prescriber The changing face of oral cancer: from biology to the bedside

Speaker:

Gareth Thomas, Professor of Experimental Pathology, University of Southampton and Consultant in Head and Neck Pathology, University Hospital Southampton NHS Foundation Trust

\section{Saturday 9 May 2015}

Early detection of oral cancer Speaker:

Simon Whitley, Consultant in Oral and Maxillofacial Surgery, Barts and the Royal London Hospitals; and Lead Clinician and Chair, Head and Neck Multidisciplinary Team, North East London NHS

\section{'GAIN DIFFERENT}

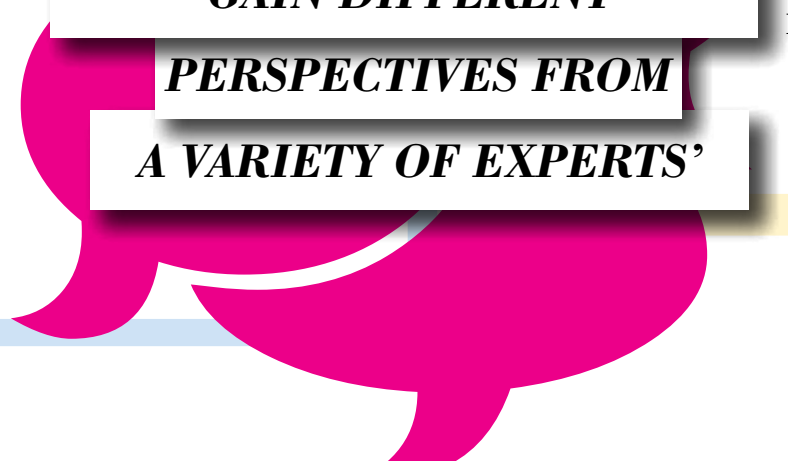

